\title{
Non-volatile free silver paste formulation for front-side metallization of silicon solar cells
}

\author{
Ceren Yüce, ${ }^{\mathrm{a}, *}$, Kuninori Okamoto ${ }^{\mathrm{b}}$, Lindsey Karpowich ${ }^{\mathrm{c}}$, Adrian Adrian ${ }^{\mathrm{d}}$, Norbert Willenbacher ${ }^{\mathrm{a}}$ \\ ${ }^{a}$ Karlsruhe Institute of Technology, Institute for Mechanical Process Engineering and Mechanics, 76131, Karlsruhe, Germany \\ ${ }^{\mathrm{b}}$ Changzhou Fusion New Material Company, Shanghai, China \\ ${ }^{\mathrm{c}}$ Heraeus Precious Metals North America Conshohocken LLC (Photovoltaic Global Business Unit), West Conshohocken, Pennsylvania, United States \\ d International Solar Energy Research Center (ISC) Konstanz, 78467, Konstanz, Germany
}

A R T I C L E IN F O

\section{Keywords:}

Additive-free silver paste formulation

Capillary suspensions

Fine line printing

High-speed imaging

Knotless screen

Pattern transfer printing

Paste rheology

Cell efficiency

EL

Electrode morphology

\begin{abstract}
A B S T R A C T
We present a versatile, cost-effective formulation platform for highly conductive silver pastes used in front-side metallization of silicon ( $\mathrm{Si}$ ) solar cells. Pastes based on the capillary suspension concept include silver particles, glass frit and two immiscible fluids. Capillary forces inferred from the second fluid added only in small fractions induce the formation of a percolating particle network. This provides extended shelf-life and distinct flow properties adjustable in a wide range as demanded by the respective printing process, thus yielding residual-free sintered electrodes. Si-wafers are successfully metallized with such pastes using conventional screen-printing, knotless screen and Pattern Transfer Printing ${ }^{\mathrm{TM}}$. Paste spreading is studied via high-speed imaging during screenprinting on glass plates. Morphology of printed lines is analyzed using laser scanning microscopy. Electrical properties of the cells are characterized employing a solar simulator and electroluminescence spectroscopy. Results are compared to those obtained using commercial pastes including the same silver particles and glass frits. Paste performance strongly depends on the selected secondary fluid. Aspect ratios $\approx 0.4-0.5$ can be reached and cell efficiencies $\eta_{\text {eff }} \approx 21 \%$ on $\mathrm{Cz}$ - and $18.6 \%$ on $\mathrm{mc}$ Si-wafers are obtained. Additional investigations are necessary to further reduce paste spreading and line interruptions thus improving cell performance.
\end{abstract}

\section{Introduction}

The global challenge of climate change pushes electric energy generation from renewable sources, utilizing photovoltaics, wind energy, hydropower, geothermal energy and biomass is strongly growing [1-3]. Photovoltaic (PV) systems, namely solar cells, play a key role due to their robustness and virtually maintenance-free operation over long time periods ( $>25$ years). Today more than $90 \%$ of the globally installed PV systems are based on silicon wafer technology which despite of its maturity still is a matter of current research $[4,5]$ and screenprinting is the dominant production technology for front- and rear-side metallization of these silicon (Si) solar cells $[6,7]$ due to its easy implementation and its high through-put (currently up to 4000 wafers $/ \mathrm{h}$ on a single line) [8]. This economically attractive technology is one of the key factors enabling the recent improvement of solar cell efficiency and cost reduction. However, already today about $7.5 \%$ of the global silver production are used for the metallization of solar cells [8]. Thus, a significant reduction of silver consumption per wafer and further enhancement of cell efficiency are essential for an expansion of PV installations. An optimization of the solar cell front-side metallization can be achieved by reducing the finger width $\mathrm{w}_{\mathrm{f}}$ and increasing the aspect ratio AR of the screen printed lines. State-of-the-art finger widths achieved by screen-printing goes down to $30 \mu \mathrm{m}$ [9]. Further reduction of $\mathrm{w}_{\mathrm{f}}<30 \mu \mathrm{m}$ and AR $>0.6$ could facilitate lower shading losses and reduce material consumption $[8,10,11]$. Screen-printing is a robust and cost-efficient production process, but the resulting finger width is limited by the mesh wire thickness and material used in conventional screen manufacturing $[6,12]$. New application technologies, such as knotless screen [12], dispensing [13], flexographic print [14], or Pattern Transfer Printing ${ }^{\mathrm{TM}}$ (PTP) [15], as well as suitable paste formulations are needed to excel the actual finger width and AR limits.

Typical commercial formulations of screen-printing pastes for frontside metallization consist of conductive material ( $85-90 \mathrm{wt} \%$ ), i.e. micron sized spherical silver particles $x_{50} \approx 1-3 \mu \mathrm{m}$, dispersed in a continuous phase (5-14 wt\%), the so-called vehicle. This is a mixture of organic solvent containing non-volatile organic binders and additives to control flow properties and to strengthen the adhesion of printed electrodes on the substrate. In addition, micron sized leaded glass frit

\footnotetext{
"Corresponding author. Tel.: + 497216084 3760; fax.: + 4972160843758.

E-mail addresses: ceren.yuece@kit.edu (C. Yüce), norbert.willenbacher@kit.edu (N. Willenbacher).
} 

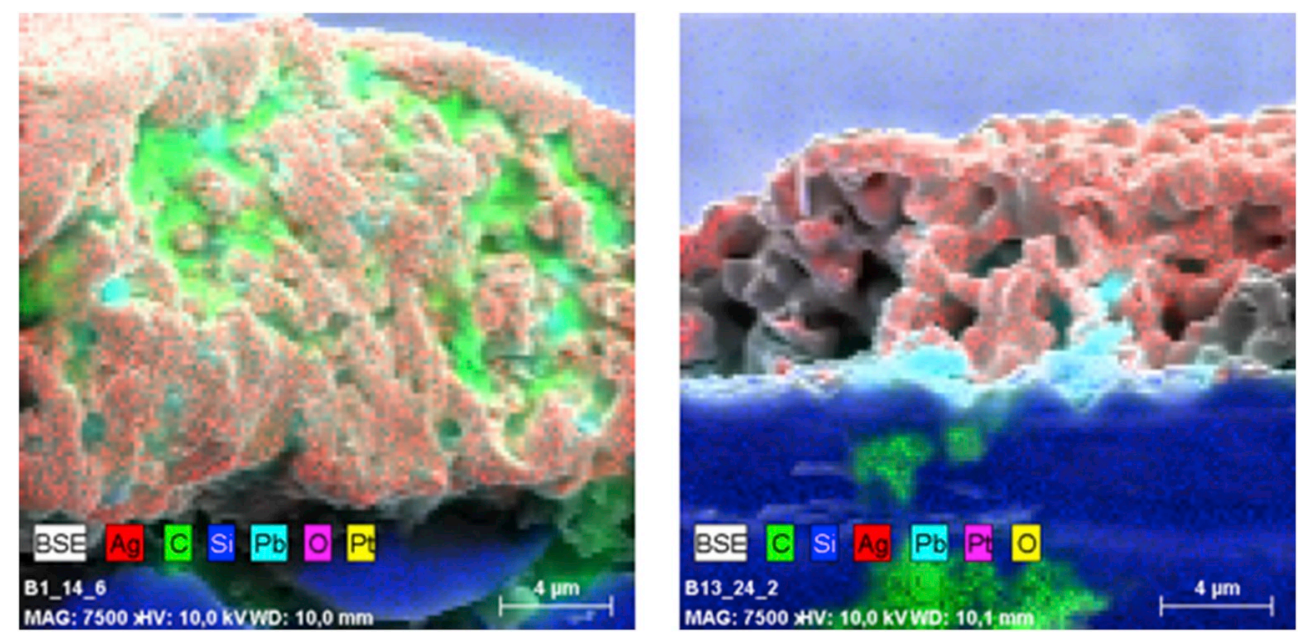

Fig. 1. Energy dispersive electron microscopy (EDX) image of screen-printed and fired commercial paste (left) and additivefree formulation paste (right) printed on a Si-wafer to demonstrate the presence of carbon impurities, here shown in green color. (For interpretation of the references to color in this figure legend, the reader is referred to the Web version of this article.)

(1-5 wt\%) is dispersed as a second solid component to etch off the antireflection layer on the wafer surface and to create a contact between the printed electrodes and the n-doped Si-wafer layer [16-22].

In this study, we present highly conductive silver pastes prepared as so-called capillary suspensions, i.e. ternary solid/fluid/fluid systems [23] without any addition of non-volatile organic components [24]. The special feature is that the used liquids, termed as bulk fluid and secondary fluid, are immiscible and accordingly a sample-spanning particle network forms driven by the capillary forces acting in the ternary system. The strength of this particle network results in a high yield stress and guarantees storage stability for several months, even with the high density difference between silver particles and continuous phase used here [23-26]. This network, however, breaks down when external stresses are applied and this results in a high degree of shear thinning which can be varied in a wide range to meet the requirements of different coating processes [26]. The flow behavior of such pastes is not only determined by the size, shape and volume fraction of the solid phase but also by the wetting properties of both fluids on the particle surface as well as the interfacial tension $\Gamma_{\text {int }}$ between bulk and secondary fluid [26]. Accordingly, a large number of liquid combinations can be chosen for silver paste formulation in combination with commercially available silver and glass frit to meet a wide range of product and process-specific requirements. Our research is motivated by the expected metallization cost reduction coming with this paste concept. The fabrication of non-volatile free pastes is simpler than that of commercial paste since the number of ingredients is lower, in particular it does not include a thixotropic agent which requires heat treatment to be dissolved or dispersed properly. This is the direct but relatively small effect on cost reduction. Beyond that, we expect a significantly better electrical performance, provided a state-of-the-art printing quality can be achieved, according to preliminary experiments [24] silver consumption may be cut by $50 \%$.

In this study, we use this new paste formulation concept together with different printing technologies: the screen-printing method with conventional standard screen as well as knotless screen, and the PTP method, for ultra-fine front-side metallization. Knotless screen is characterized by the $0^{\circ}$ mesh angle, which is the orientation of the mesh wire to the screen frame and hence the direction of finger lines. The advantage is that the wire intersections in the open channels which are known from the $22.5^{\circ}$ orientated mesh wires in conventional screens are absent here. Due to less wires crossing the mesh openings, so-called mesh marks are reduced, paste transfer is expected to be enhanced, finger uniformity should be improved and a better conductivity is expected even at lower finger width [12,27]. Recently, finger widths of $\mathrm{w}_{\mathrm{f}}=28 \mu \mathrm{m}$ could be obtained using knotless screen design [28]. PTP is a contactless printing technology based on laser induced paste deposition from a polymer substrate, so-called tape. This method enables the manufacturing of ultra-fine finger lines $(<20 \mu \mathrm{m})$ with high aspect ratio $(>0.6)$ since the trench width and height in the typically used tapes are $20 \mu \mathrm{m}[15,29]$.

The high conductivity of silver pastes based on capillary suspensions is demonstrated in preliminary lab scale stencil printing test. A twofold increase of conductivity compared to layers produced from commercial pastes under identical conditions could be gained [24]. The non-volatile organic additives in commercial silver paste formulations do not necessarily burn out without residues during sintering. Thus, small amounts of residual carbon can considerably worsen the conductivity of the printed layer. These residues are demonstrated in sintered electrodes made from a commercial paste using energy dispersive electron microscopy (EDX) imaging here (Fig. 1).

In the cross-section of sintered finger lines made from a commercial silver pastes residual carbon ( $\mathrm{C}=$ green color) is evident, while in the electrode cross-section of the additive-free capillary suspension type paste no carbon is detected. The absence of non-volatile components should result in higher finger line conductivity since the electrical conductivity is not disturbed by impurities. However, this is not proven experimentally yet due to a lack of data for printed lines with similar cross-section and longitudinal uniformity made from both types of paste.

Furthermore, burned-out polymeric binders are likely to contaminate the sintering furnace and ventilation ductwork and residues may cause unexpected changes to the sintering furnace performance, excessive downtime for maintenance and possible fire hazard as carbonaceous residues accumulate within ventilation ductwork. Cleanburning binder systems have been developed to reduce these detriments [30]. Our paste formulations based on the capillary suspension concept offer an inherent benefit with respect to the sintering process since paste stabilization is done with volatile solvents only.

We prepare pastes with different composition and determine rheological parameters relevant for paste characterization, as described in Refs. [31,32] considering paste rheology to be relevant for printing performance [33]. Furthermore, a detailed investigation of finger line morphology obtained from standard screen printing is done to understand the relationship between paste composition, its rheological properties and line shape as well as its impact on cell performance. Analysis of line morphology right after printing, drying, and firing elucidates the change in finger line during the drying and sintering steps. High-speed imaging experiments [34] are performed to capture finger shape development for additive-free suspensions during standard screen-printing. 
Table 1

Viscosity values of various bulk fluid composition mixtures used for the capillary suspension formulation.

\begin{tabular}{lll}
\hline glycerol content/wt\% & ethylene glycol content/wt\% & $\begin{array}{l}\text { bulk fluid viscosity } \\
\eta_{\text {bulk }} / \mathrm{mPas}\end{array}$ \\
\hline 0 & 100 & $20 \pm 1$ \\
20 & 80 & $36 \pm 1$ \\
40 & 60 & $77 \pm 2$ \\
60 & 40 & $166 \pm 3$ \\
80 & 20 & $404 \pm 14$ \\
100 & 0 & $1060 \pm 9$ \\
\hline
\end{tabular}

\section{Experimental procedure}

\subsection{Materials}

Capillary suspensions are ternary solid/fluid/fluid systems. The bulk fluids used in this work are mixtures of two polar liquids, glycerol (Carl Roth, Germany) and ethylene glycol (VWR, Germany). The amount of ethylene glycol dissolved in glycerol is varied between 0 and $100 \mathrm{wt} \%$ corresponding to a variation in viscosity between $20 \mathrm{mPas}$ and $1060 \mathrm{mPas}$ (Table 1).

Three proprietary mixtures of nonpolar volatile organic solvents (termed SF1, SF2, and SF3) differing in their boiling point $\left(215^{\circ} \mathrm{C}, 244\right.$, and $260^{\circ} \mathrm{C}$ ) are used as secondary fluid. All of them are immiscible with the above mentioned bulk mixtures. Further differences are obtained for the interfacial tension $\Gamma_{\text {int }}$ between bulk and secondary fluid determined with the pendant drop method [35-37], values vary between $1.6 \mathrm{mN} / \mathrm{m}$ and $11.2 \mathrm{mN} / \mathrm{m}$ depending on the selected liquid combination (see supplementary, Figure 14). In one series of pastes $\Gamma_{\text {int }}$ is decreased by increasing the ethylene glycol content of the bulk fluid, in a second series interfacial tension is varied using SF1, SF2, or SF3 together with one specific bulk system.

For conductive front-side metallization pastes, we use micron sized, almost spherical and hydrophobically modified silver (Ag) particles (type $\mathrm{T}, \mathrm{H}$, and $\mathrm{M}$, Fig. 2). Type $\mathrm{M} \mathrm{Ag}$ particles, product number $\mathrm{K}-7418 \mathrm{P}$, are purchased from Metalor Technologies (UK) Ltd., type $\mathrm{T}$ is provided by the industrial partner, Changzhou Fusion New Material Company (China) and type $\mathrm{H}$ by Heraeus Photovoltaics (United States).

Contact angle measurements on silver surface are performed according to the sessile drop method [38-40]. The contact angle of a water drop on silver tablet made from the particles mentioned above in air environment is $\Theta=123.1 \pm 3.5^{\circ}$ for type $\mathrm{T}, \Theta=132.5 \pm 2.5^{\circ}$ for type $\mathrm{H}$, and $\Theta=110.0 \pm 3.9^{\circ}$ for type $M$. All determined values are higher than $90^{\circ}$ and hence all types of silver particles are classified as hydrophobic. Surface energies $\Gamma_{\text {surface }}$ (see supplementary, Figure 13) are calculated from measured contact angles for a series of liquids according to the method of Owens and Wendt [41]. These are in the range of $\Gamma_{\text {surface }} \sim 40-60 \mathrm{mN} / \mathrm{m}$, which further suggests that the particles used here are not behaving like precious metals since the expected surface energy $\Gamma_{\text {surface }}$ for pure silver $\Gamma_{\text {surface, pure Ag }}=1250 \mathrm{mN} / \mathrm{m}$ is several orders of magnitude higher. Surface energy measurements confirm that the silver particles are surface modified particles to facilitate the dispersibility in nonpolar organic solvent.
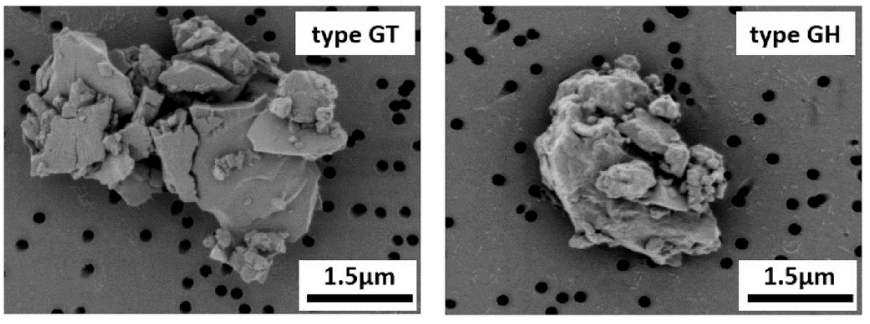

Fig. 3. SEM images of micron sized glass frit type GT and GH.

Table 2

Overview of particle size distribution for silver particles type $\mathrm{T}, \mathrm{H}$, and $\mathrm{M}$ as well as for glass frit type GT and $\mathrm{GH} ; \mathrm{x}_{10}$ is the 10th percentile of all particle diameters, which means that $10 \%$ of the observations are less than the $\mathrm{x}_{10}$ value, $x_{50}$ is the median, corresponds to the 50th percentile, and $x_{99}$ is the 99th percentile, these values are determined using Fraunhofer diffraction.

\begin{tabular}{|c|c|c|c|}
\hline \multicolumn{4}{|c|}{ silver particle } \\
\hline type & $\mathbf{x}_{10} / \mu \mathrm{m}$ & $\mathbf{x}_{50} / \mu \mathrm{m}$ & $\mathbf{x}_{99} / \mu \mathrm{m}$ \\
\hline $\mathrm{T}$ & $1.12 \pm 0.02$ & $2.19 \pm 0.01$ & $5.12 \pm 0.11$ \\
\hline $\mathrm{H}$ & $0.97 \pm 0.10$ & $2.53 \pm 0.07$ & $9.27 \pm 0.55$ \\
\hline M & $1.08 \pm 0.03$ & $2.05 \pm 0.06$ & $4.78 \pm 0.02$ \\
\hline \multicolumn{3}{|c|}{ glass frit } & $\mathrm{x}_{99} / \mu \mathrm{m}$ \\
\hline GT & $0.53 \pm 0.01$ & $2.66 \pm 0.04$ & $11.85 \pm 4.12$ \\
\hline GH & $0.25 \pm 0.01$ & $1.08 \pm 0.03$ & $9.51 \pm 0.03$ \\
\hline
\end{tabular}

Table 3

Three-phase contact angle $\Theta_{C}$ of SF1 or SF2 droplets formed on silver tablets made of type $\mathrm{T}, \mathrm{H}$, and $\mathrm{M}$ silver particles surrounded by a mixture of $60 \mathrm{wt} \%$ ethylene glycol dissolved in glycerol.

\begin{tabular}{llll}
\hline Ag particle & $\Theta_{\mathrm{C}, \mathrm{SF} 1}$ & $\Theta_{\mathrm{C}, \mathrm{SF} 2}$ & capillary network $[42,43]$ \\
\hline type $\mathrm{T}$ & $29.5 \pm 3.8^{\circ}$ & $24.8 \pm 4.5^{\circ}$ & pendular state \\
type $\mathrm{H}$ & $19.1 \pm 2.4^{\circ}$ & $16.8 \pm 2.5^{\circ}$ & pendular state \\
type M & $101.4 \pm 1.1^{\circ}$ & $108.0 \pm 5.5^{\circ}$ & capillary state \\
\hline
\end{tabular}

To ensure electrode contacting during the fast firing process we also add micron sized leaded glass frit (type GT and GH, Fig. 3). Glass frit type GT is provided by Changzhou Fusion New Material Company (China) and type GH by Heraeus Photovoltaics (United States).

Particle size distributions are determined using Fraunhofer diffraction and corresponding data are listed in Table 2.

Three-phase contact angle $\Theta_{C}$ measurements [38-40] are performed for a SF1 and SF2 droplet on silver tablets made from Ag particles of type $\mathrm{T}, \mathrm{H}$, and $\mathrm{M}$ surrounded by $60 \mathrm{wt} \%$ ethylene glycol dissolved in glycerol (Table 3 ). For both fluids the three-phase contact angle $\Theta_{C}$ on $\mathrm{Ag}$ type $\mathrm{T}$ and $\mathrm{H}$ is well below $90^{\circ}$, and therefore it can be concluded that a pendular state network is formed in the corresponding capillary suspensions. For Ag type $\mathrm{M}$ a capillary state network structure is formed since $\Theta_{\mathrm{C}}>90^{\circ}[42,43]$. Within experimental accuracy the wetting
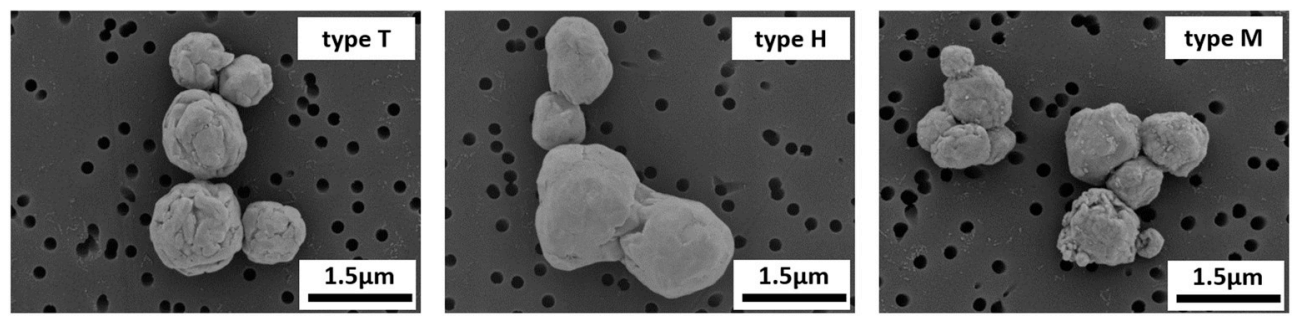

Fig. 2. SEM images of micron sized spherical silver particles type T, H, and M. 
Table 4

Additive-free paste formulations P1 - P9 applied for standard screen printing experiments made of $\varphi_{\mathrm{Ag}}=87.1 \mathrm{wt} \%$ ( $=47.4 \mathrm{vol} \%$ ) T-type silver particles and $\varphi_{\text {glass }}$ frit $=2.25 \mathrm{wt} \%$ (=4.8 vol\%) GT-type glass frit. Pastes differ in composition of bulk fluid as well as type and amount of secondary fluid.

\begin{tabular}{|c|c|c|c|c|}
\hline label & bulk fluid composition glycerol content/wt $\%$ & secondary fluid type and amount/vol\% & $\begin{array}{l}\text { yield stress } \\
\tau_{\mathrm{y}} / \mathrm{Pa}\end{array}$ & slope of wall slip velocity $\partial \mathrm{v}_{\text {slip }} / \partial \tau / \mu \mathrm{m} / \mathrm{Pas}$ \\
\hline P1 & 80 & SF1 - 5 & $1479 \pm 178$ & - \\
\hline P2 & 60 & SF1 - 3 & $916 \pm 80$ & $3.3 \pm 0.2$ \\
\hline P3 & 60 & SF1 - 5 & $1153 \pm 160$ & $8.6 \pm 2.6$ \\
\hline P4 & 60 & SF1 - 9 & $1379 \pm 198$ & - \\
\hline P5 & 40 & SF1 - 5 & $836 \pm 30$ & $9.1 \pm 0.2$ \\
\hline P6 & 60 & SF2 - 5 & $1583 \pm 38$ & $6.5 \pm 0.3$ \\
\hline P7 & 40 & SF2 - 5 & $661 \pm 55$ & - \\
\hline P8 & 40 & SF2 - 9 & $1002 \pm 49$ & $8.1 \pm 0.2$ \\
\hline P9 & 100 & SF3 - 5 & $1014 \pm 16$ & $5.9 \pm 0.6$ \\
\hline
\end{tabular}

behavior of fluids SF1 and SF2 is similar on all three types of silver particles.

Composition and characteristic parameters of pastes used in the different printing experiments are summarized in Table 4, Table 5, Table 6, and Table 7 shown in chapter 3.

\subsection{Process route for silver paste preparation}

The process route for silver paste preparation (Fig. 4) based on the capillary suspension concept is fast and simple compared to commercial silver paste manufacturing. Processing time is decreased since additives typically included in commercial silver pastes which are activated at

\section{Table 5}

Compositions of pastes used for high-speed imaging experiments. Pastes contain $\varphi_{\mathrm{Ag}}=82.0 \mathrm{wt} \%$ ( $=35 \mathrm{vol} \%$ ) silver particles type M. The bulk fluid used for all pastes is pure glycerol and the secondary fluid content is $5 \mathrm{vol} \%$. Type of secondary fluid is different for pastes P10 - P12. These formulations include no glass frit.

\begin{tabular}{llll}
\hline label & $\begin{array}{l}\text { secondary liquid type } \\
\text { and amount/vol\% }\end{array}$ & $\begin{array}{l}\text { yield stress } \\
\tau_{\mathrm{y}} / \mathrm{Pa}\end{array}$ & $\begin{array}{l}\text { slope of wall slip velocity } \\
\partial \mathrm{v}_{\text {slip }} / \partial \tau / \\
\mu \mathrm{m} / \mathrm{Pas}\end{array}$ \\
\hline P10 & SF1 -5 & $1153 \pm 123$ & $0.9 \pm 0.1$ \\
P11 & SF2 -5 & $1451 \pm 30$ & $1.1 \pm 0.2$ \\
P12 & SF3 -5 & $416 \pm 7$ & $0.8 \pm 0.1$ \\
\hline
\end{tabular}

\section{Table 6}

Composition of pastes used for knotless screen printing tests. These pastes are made of H-type silver particles $\varphi_{\mathrm{Ag}}=88.8 \mathrm{wt} \%$ ( $=52.1 \mathrm{vol} \%$ ), GH-type glass frit $\varphi_{\text {glass frit }}=2.64 \mathrm{wt} \%$ ( $\left.=6.2 \mathrm{vol} \%\right)$, and SF1 $(5 \mathrm{vol} \%)$ as secondary liquid. Yield stress and the slope of wall slip vs. shear stress of pastes P13 - P15 and the commercial reference $\mathrm{H}$ are listed. Differences in FOG $=11 \pm 2 \mu \mathrm{m}$ are within experimental error.

\begin{tabular}{llll}
\hline label & $\begin{array}{l}\text { bulk fluid composition } \\
\text { glycerol content/wt } \%\end{array}$ & $\begin{array}{l}\text { yield stress } \\
\tau_{\mathrm{y}} / \mathrm{Pa}\end{array}$ & $\begin{array}{l}\text { slope of wall slip velocity } \\
\partial \mathrm{v}_{\text {slip }} / \partial \tau / \\
\mu \mathrm{m} / \mathrm{Pas}\end{array}$ \\
\hline P13 & 80 & $1514 \pm 47$ & $12 \pm 1$ \\
P14 & 40 & $846 \pm 36$ & $37 \pm 3$ \\
P15 & 20 & $608 \pm 57$ & $72 \pm 3$ \\
reference H & - & $780 \pm 8$ & $41 \pm 4$ \\
\hline
\end{tabular}

elevated temperature to form a sample-spanning network in the fluid phase are not included [44].

All components (silver particles, glass frit, bulk and secondary liquid) are placed in a bottle (1) and then mixed for $30 \mathrm{~s}$ at $2000 \mathrm{rpm}$ using a non-contact planetary mixer (SpeedMixer ${ }^{\mathrm{TM}}$, Hauschild GmbH) (2). Capillary bridges are formed between the particles, but a few agglomerates are still present in the paste (3). Thus, the subsequent use of a three-roll mill (EXAKT 80E, EXAKT Advanced Technologies GmbH) is essential to break agglomerates by changing the gap distance stepwise from $40 \mu \mathrm{m}$ down to $7 \mu \mathrm{m}$. The processing speed for de-agglomeration is set to $90 \mathrm{rpm}$ (4). Obtained pastes include air bubbles after the milling process due to the high paste viscosity (5). These bubbles are removed using the non-contact planetary mixer with the same settings as in the previous mixing step (6). Following these steps allows to create a homogenous and agglomerate-free silver paste which is also stabilized against sedimentation due to the formed capillary bridges between the solid particles (7). Storage stability is checked after 6 months, 1 year, and 2 years. Pastes do not dry and no phase separation is observed. For commercial pastes phase separation typically occurs after 6 months.

\subsection{Paste characterization}

Various rheological parameters considered to be relevant for screenprinting of conductive pastes are determined according to experimental protocols especially suited for highly filled silver pastes [31]. All experiments are conducted at $\mathrm{T}=23^{\circ} \mathrm{C}$.

Yield stress measurements are performed using a stress controlled rheometer setup (Haake RS150, Thermo Fisher Scientific) equipped with a vane-and-cup fixture. Measurements are conducted applying a stepwise controlled stress mode, varying the stress from 1 to $5000 \mathrm{~Pa}$ in 41 steps equally separated on a logarithmic scale, while each stress is applied for $30 \mathrm{~s}$. The yield stress is defined as the stress at which the sample begins to flow irreversibly and here it is determined from deformation vs. stress data according to the tangent intersection point method $[31,45,46]$.

Wall slip velocity $\mathrm{v}_{\text {slip }}$ is determined in a parallel-plate rheometer (Haake RS150) using a smooth upper stainless steel plate (plate roughness $R_{q}=1 \mu \mathrm{m}$, plate radius $r=10 \mathrm{~mm}$, gap height $h=1 \mathrm{~mm}$ ) and a rough bottom plate $\left(R_{q}=9 \mu \mathrm{m}\right)$ to assure that slip takes place only at the upper plate, but the rest of the sample remains undeformed [47]. Then $\mathrm{v}_{\text {slip }}=2 \pi n r$, where $\mathrm{n}$ is the rotational speed of the plate. According to Ref. [47] absolute $\mathrm{v}_{\text {slip }}$ values may be significantly

Table 7

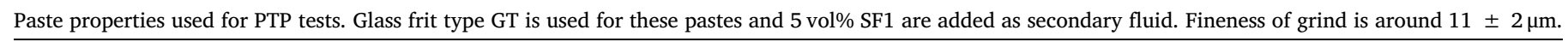

\begin{tabular}{lllllll}
\hline label & bulk fluid composition glycerol content/wt\% & silver particle type & silver particle content & $\begin{array}{l}\text { glass frit } \\
\text { content/wt } \%\end{array}$ & $\begin{array}{l}\text { yield stress } \\
\tau_{\mathrm{y}} / \mathrm{Pa}\end{array}$ & $\begin{array}{l}\text { slope of wall slip velocity } \\
\partial \mathrm{v}_{\text {slip }} / \partial \tau / \\
\mu \mathrm{m} / \mathrm{Pas}\end{array}$ \\
\hline P16 & 40 & & & & & \\
$\mathrm{P} 17$ & 20 & $\mathrm{~T}$ & $87.0 \mathrm{wt} \%(48 \mathrm{vol} \%)$ & 2.6 & $959 \pm 111$ & $17.8 \pm 2.1$ \\
& $\mathrm{M}$ & $87.9 \mathrm{wt} \%(50 \mathrm{vol} \%)$ & 2.9 & $1633 \pm 110$ & $52.1 \pm 3.5$ \\
\hline
\end{tabular}



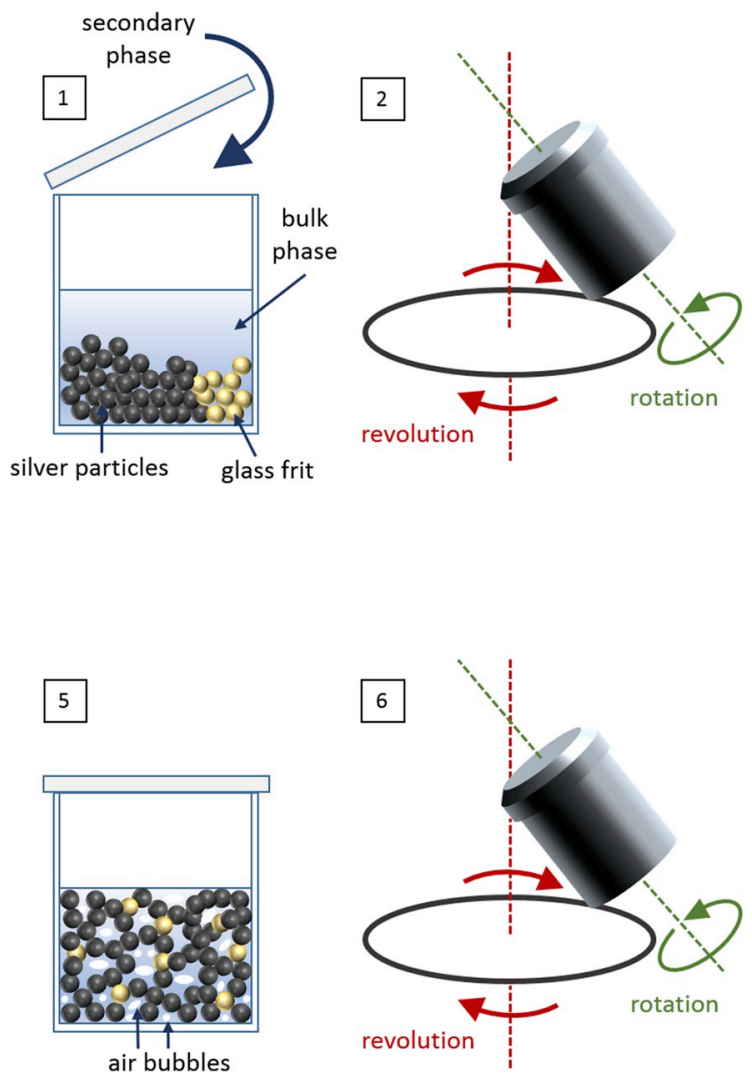
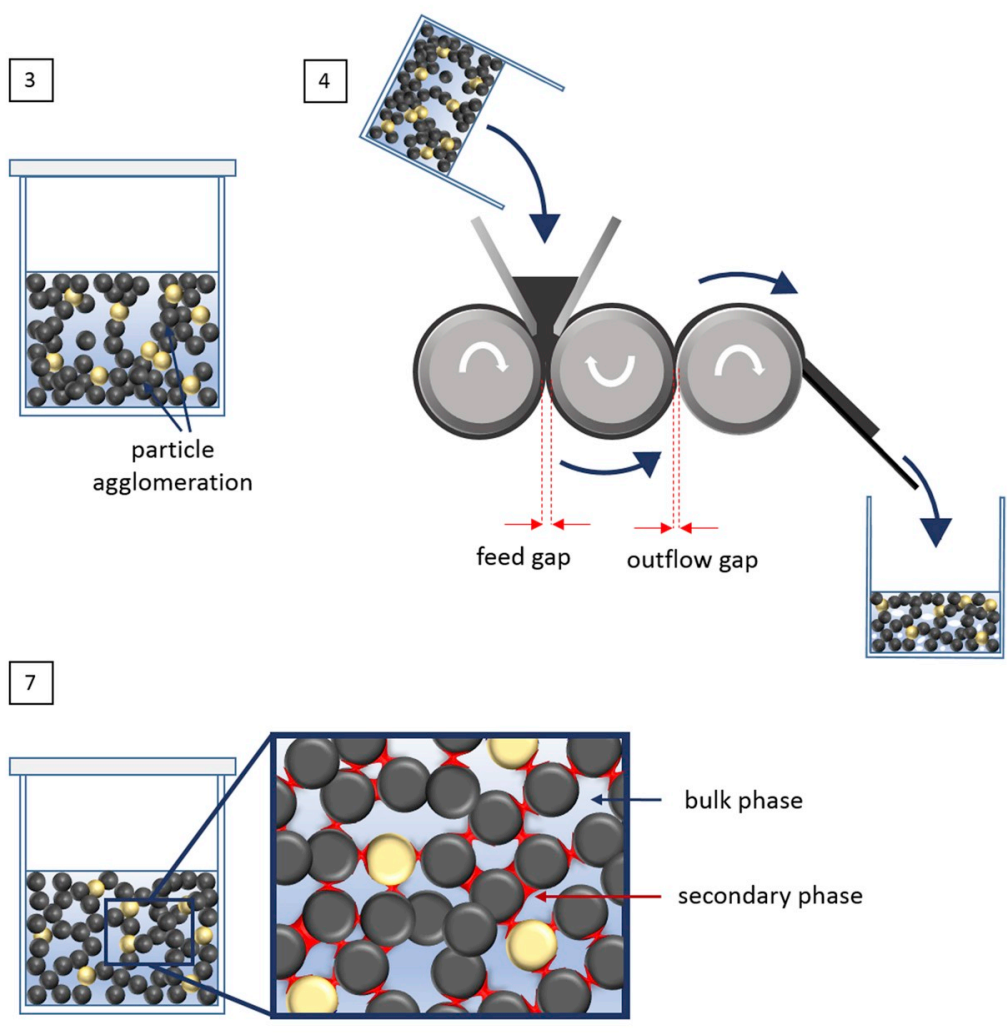

Fig. 4. Process route for silver paste preparation based on the capillary suspension concept using a non-contact planetary mixer and a three-roll mill for manufacturing of homogeneous additive-free pastes. Sample preparation steps are (1) the addition of all components into one mixing bottle, (2) homogenization of the components with a non-contact planetary mixer, (3) sample-spanning network formation in the paste with visible agglomerates, (4) subsequent paste homogenization with a three-roll mill, $(5+6)$ removal of air bubbles using the non-contact planetary mixer, (7) finally the homogeneous sample-spanning network formation in capillary suspension without agglomerates and air bubbles; see text for more details.

different on emulsion polymer, which is more relevant for the printing process, compared to a stainless steel surface. The relative changes due to modification of the paste composition, however, can be assumed to be similar for both substrates.

The size of the largest agglomerates in the silver pastes is determined based on the grindometer test. This test utilizes a precisely fabricated bar of stainless steel with parallel spaced grooves in a planar surface. The grooves have a start depth of $25 \mu \mathrm{m}$ and linearly decrease towards $0 \mu \mathrm{m}$ at the opposite end of the bar. A small amount of silver paste is placed between a blade and the grooves at $25 \mu \mathrm{m}$ depth and the blade is moved along the grooves which are filled up with the paste. Resulting scratches in the lane indicate the presence of particle agglomerates. The so-called fineness of grind FOG value is set as the depth of the groove position where the fourth scratch occurres.

\subsection{Printing technology, electrode morphology and cell performance characterization}

\subsubsection{Standard screen}

Printing tests with standard screen are performed at Changzhou Fusion New Material Company (Shanghai, China). Front-side metallization with a conventional screen (360 meshes per inch, $16 \mu \mathrm{m}$ mesh wire diameter, $16 \mu \mathrm{m}$ emulsion over mesh (EOM) thickness, 96 fingers with $37 \mu \mathrm{m}$ finger opening, and 5 busbars) (Murakami Screen) is carried out on an industrial semiautomatic screen printer (Baccini Soft Line). The used squeegee (Youlan Solar) has a 65 shore hardness and forms a $60^{\circ}$ angle with the screen. Metallization is performed at $150 \mathrm{~mm} / \mathrm{s}$ printing speed and $400 \mathrm{~mm} / \mathrm{s}$ flooding speed. The snap-off distance is fixed at $\mathrm{h}_{\text {snap-off }}=1.9 \mathrm{~mm}$. We print 10 multicrystalline Si-wafer (TrinaSolar, diamond wire cut, wafer size, $152.4 \times 152.4 \mathrm{~mm}^{2}$ ) per paste. The rear-side is metallized with aluminum paste (normal BSF). These printed substrates are dried and fired in an industrial belt furnace (CF-series, Despatch Industries) at a process speed of $\mathrm{v}_{\text {belt }}$ furnace $=6.35 \mathrm{~m} / \mathrm{min}$ and 9 temperature zones within $100 \mathrm{~s}$. Here, last remaining organic components of the pastes are burned out at around $\mathrm{T} \approx 500^{\circ} \mathrm{C}$ before the contact formation of printed electrode and substrate starts at the firing peak temperature $\mathrm{T}_{\text {peak }}=740^{\circ} \mathrm{C}$.

The electrode morphology is examined with a 3D laser scanning microscope (Keyence VK-X200srs). The finger profile, i.e. width $\mathrm{w}_{\mathrm{f}}$ and height $h_{f}$, are directly measured and the respective aspect ratio $\mathrm{AR}=\mathrm{h}_{\mathrm{f}} / \mathrm{w}_{\mathrm{f}}$, is calculated. Characterization is done at different positions of three printed wafers to get an overview of substrate contacting. Furthermore, cell performance characterization (short circuit current $\mathrm{J}_{\mathrm{SC}}$, open circuit voltage $\mathrm{V}_{\mathrm{OC}}$, fill factor FF, and cell efficiency $\eta_{\text {eff }}$ ) is performed by current vs. voltage (I-V) measurements on a solar simulator (Pasan Lab cell tester).

In addition, we investigate the finger line width right after printing, drying, and firing for standard screen printing tests. Therefore, finger height profile images are captured with a 3D laser scanning microscope and AR is determined always at the same position to evaluate the differences between printed, dried and fired electrodes. The substrates are dried at $\mathrm{T}_{\text {dry }}=200{ }^{\circ} \mathrm{C}$ and are fired at $\mathrm{T}_{\text {peak }}=740^{\circ} \mathrm{C}$.

Paste spreading and finger width development of additive-free pastes during the screen-printing process with a standard screen is further observed with high-speed imaging system described in Ref. [34]. A modified commercial screen printer (EKRA E2, ASYS Group) and a high-speed camera (MotionBLITZ EoSens ${ }^{\circ}$ mini, Mikrotron $\mathrm{GmbH}$ ) with an Olympus LMPLFLN 10X objective are used to capture the paste flow through a standard screen (360 meshes per inch, $16 \mu \mathrm{m}$ mesh wire diameter, $22 \mu \mathrm{m}$ EOM thickness, and 102 fingers with $35 \mu \mathrm{m}$ 


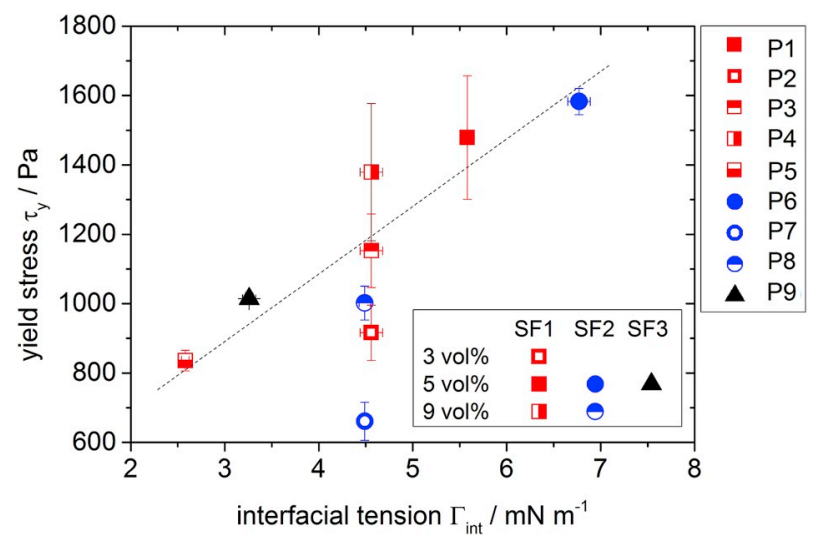

Fig. 5. Yield stress values for additive-free pastes with different amount of secondary fluid and different interfacial tension $\Gamma_{\text {int }}$ between bulk and secondary fluid.

finger opening) (Brave, Taiwan) from underneath. Pastes are printed on a $1 \mathrm{~cm}$ thick transparent glass plate which is placed on a movable substrate table. We record the printing process with a frame rate of $1000 \mathrm{fps}$ and a resolution of $1708 \times 832$ pixels corresponds to 0.724 $\mu \mathrm{m} /$ pixel. The used squeegee (BASF Taiwan) has a 75 shore hardness and formes a $60^{\circ}$ angle with the screen. Printing tests are performed at $100 \mathrm{~mm} / \mathrm{s}$ printing speed and snap-off distance is fixed at $h_{\text {snap- }}$ off $=1.6 \mathrm{~mm}$. More detailed information about the test protocol and process parameters can be found in Ref. [34].

\subsubsection{Knotless screen}

Front-side metallization with knotless screen (290 meshes per inch, $20 \mu \mathrm{m}$ mesh wire diameter, $15 \mu \mathrm{m}$ EOM thickness, and 101 fingers with $27 \mu \mathrm{m}$ finger opening) (Sanyo Super Screen) is performed at Heraeus Photovoltaics (Conshohocken, Pennsylvania, USA). Printing tests are carried out on an industrial screen printer (EKRA E2, ASYS Group). The used squeegee has a 75 shore hardness and formed a $60^{\circ}$ angle with the screen. Metallization is performed at $50 \mathrm{~mm} / \mathrm{s}$ printing speed and $100 \mathrm{~mm} / \mathrm{s}$ flooding speed. The commercial reference paste is printed at $300 \mathrm{~mm} / \mathrm{s}$ and flooding is done at $400 \mathrm{~mm} / \mathrm{s}$. The snap-off distance is fixed at $\mathrm{h}_{\text {snap-off }}=2.2 \mathrm{~mm}$. Four multicrystalline $\mathrm{Si}$-wafer per paste are printed. The rear-side is metallized with commercial aluminum paste (Al-BSF, deposit is around $1.2 \mathrm{~g}$ per cell). In the next step these printed substrates are dried in a convection-dryer at $150{ }^{\circ} \mathrm{C}$ for $10 \mathrm{~min}$. After that, the high temperature contact firing step is performed in an industrial belt furnace including 6 temperature zones (Centrotherm 1) at a process speed of $\mathrm{v}_{\text {belt furnace }}=6.5 \mathrm{~m} / \mathrm{min}$. Here, last remaining organic components of the pastes are burned out at around $\mathrm{T} \approx 500{ }^{\circ} \mathrm{C}$ before the contact formation of printed line and solar cells took place at the firing peak temperature $\mathrm{T}_{\text {peak }}=817^{\circ} \mathrm{C}$.

The electrode morphology is examined with a $3 \mathrm{D}$ laser scanning microscope (Zeta from KLA-Tencor) to determine finger width, height and corresponding aspect ratio AR. These values are determined at different positions. Furthermore, the solar cells are analyzed using electroluminescence (EL) spectroscopy to get an overview of contacting defects on the substrate [48].

\subsubsection{Pattern Transfer printing}

Pattern Transfer Printing ${ }^{\mathrm{TM}}$ (PTP) [15] experiments are performed with the Utilight Ltd. (Yavne, Israel) device at ISC Konstanz (Germany). The pastes are applied using two doctor blades on a transparent polymer substrate with 112 pre-embossed trenches (trench width $\mathrm{w}_{\text {trench }}=30 \mu \mathrm{m}$, trench height $\mathrm{h}_{\text {trench }}=20 \mu \mathrm{m}$ ). Afterwards, the transfer of the paste pattern to the substrate is induced by laser light irradiation (wavelength $=1064 \mathrm{~nm}$ ). The dissipated high energy locally increases the temperature above the boiling point of the solvent included in the paste, the resulting gas pressure delaminates the paste from the polymer substrate and it is deposited on the wafer underneath. The gap between polymer substrate and the wafer is set to $200 \mu \mathrm{m}$. Here, we use 15 precursors per paste made of $156.75 \times 156.75 \mathrm{~mm}^{2}$ monocrystalline Si-wafer with passivated emitter and rear cell structure (PERC). Rear-side metallization with aluminum paste (Al-BSF) as well as six busbars on the front-side is already screen-printed on the precursor by the manufacturer. Substrates with applied front-side metallization are dried at $\mathrm{T}_{\text {peak }}=200^{\circ} \mathrm{C}$ using a Baccini drying oven with one drying cycle for $10 \mathrm{~min}$. The firing process is performed in a fast firing furnace (c.FIRE, Centrotherm AG) with a peak temperature of $\mathrm{T}_{\text {peak }}=930^{\circ} \mathrm{C}$ and belt process speed of $\mathrm{v}_{\text {belt furnace }}=7 \mathrm{~m} / \mathrm{min}$.

Finger width, finger height and cross-sectional area are evaluated with a 3D laser scanning microscope (Olympus) and the aspect ratio is calculated. Cell performance is characterized by I-V-curve measurements using a solar simulator (h.a.l.m. flasher, h.a.l.m. elektronik $\mathrm{GmbH}$ ) and EL spectroscopy image analysis (LumiSolarCell, Greateyes $\mathrm{GmbH}$ ) is performed to characterize contacting. With the LumiSolarCell installation it is possible to conduct the measurement with up to 5 busbars and we have to relinquish the sixth busbar present on the cells used here. Two stripes (stripe width $=22 \mu \mathrm{m}$ ) for each cell are used to determine the line resistance value of randomly selected 20 contact fingers using the four-point-probe method $[49,50]$.

\section{Results and discussion}

\subsection{Standard screen printing experiments}

Printing tests through a standard screen with $37 \mu \mathrm{m}$ finger opening are performed with nine additive-free silver pastes (Table 4). All pastes are made from T-type Ag particles and GT-type glass frit. The fraction of silver particles $(87.1 \mathrm{wt} \%)$ and glass frit $(2.25 \mathrm{wt} \%)$ is kept constant. The pastes have a low degree of agglomeration with FOG values varying between 7 and $12 \mu \mathrm{m}$.

The yield stress of the pastes varies in a wide range (600 Pa $\left.<\tau_{\mathrm{y}}<1600 \mathrm{~Pa}\right)$ depending on sample composition. Corresponding data in Fig. 5 demonstrate that $\tau_{\mathrm{y}}$ increases almost linearly with interfacial tension $\Gamma_{\text {int }}$ between bulk and secondary fluid, and at a fixed $\Gamma_{\text {int }}$ the yield stress increases with increasing secondary fluid content as expected for capillary suspensions [26].

The high shear viscosity $\eta_{\text {high }}$ of the pastes is not measured directly here because capillary rheometry experiments require a large amount of sample. It is well known that $\eta_{\text {high }}$ depends on the particle volume fraction $\varphi$ and the viscosity of the suspending medium $\eta_{\text {bulk, }}$ i. e. the composition of the bulk fluid (Table 1 ). Accordingly, $\eta_{\text {high }}$ varies with the mixing ratio ethylene glycol/glycerol. For capillary suspensions the high shear viscosity can be well approximated by that of hard sphere suspensions and since the volume fraction for the series of pastes investigated here is $\varphi=0.5=$ constant, $\eta_{\text {high }} \approx 10 \eta_{\text {bulk }}[51]$.

The slopes of wall slip velocity $\partial \mathrm{v}_{\text {slip }} / \partial \tau$ determined from $\mathrm{v}_{\text {slip }}$ versus shear stress curves (see supplementary, Figure 17) vary in a narrow range, but increase systematically with decreasing bulk fluid viscosity. The slip velocities measured here are much higher than for typical commercial pastes [31,47].

Fig. 6(a) displays the paste laydown on the substrate determined right after printing as a function of the pastes yield stress, results for the commercial reference paste $\mathrm{T}$ are shown for comparison. The laydown for seven out of nine additive-free pastes is in the range between $110 \mathrm{mg}$ and $125 \mathrm{mg}$, similar as for the commercial paste $\mathrm{T}$ and seems not to depend on yield stress $\tau_{\mathrm{y}}$. Only two samples using SF2 as secondary fluid show a significantly lower paste deposit. The reason for this is not clear yet. The wetting properties of the pastes on the Si-wafer are very similar. Supplementary Fig. 15 shows that the contact angle between multi-crystalline Si-wafer and bulk fluid increases weakly with increasing ethylene glycol content in the bulk fluid, but for the three pastes including SF2 this variation is small. Furthermore, it should be 

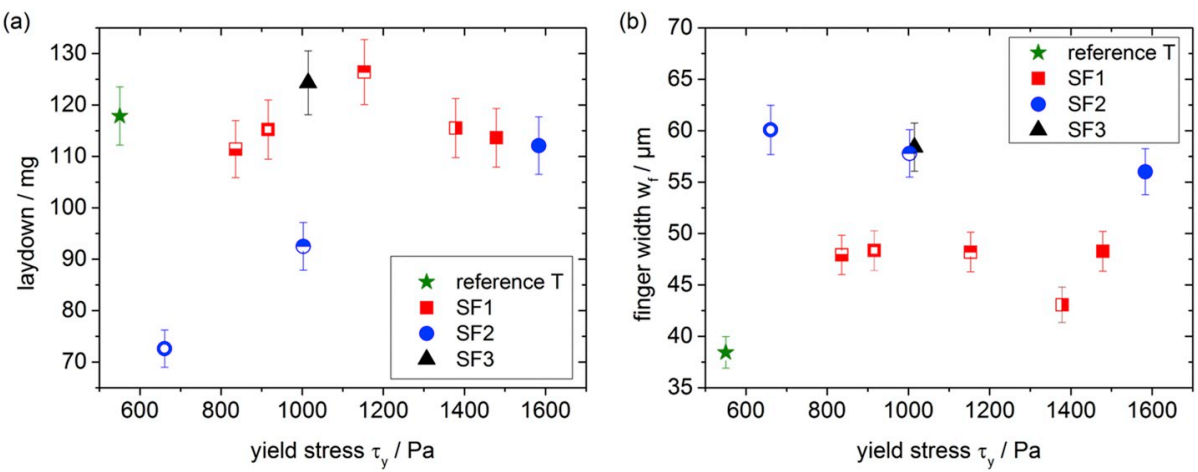

Fig. 6. (a) Paste laydown versus yield stress for additive-free formulations based on the capillary suspension concept containing SF1, SF2, and SF3. Corresponding results of two trials with commercial paste $\mathrm{T}$ are shown for reference. (b) Finger width versus yield stress for electrodes made from additive-free silver paste formulations based on the capillary suspension concept using SF1, SF2, and SF3 as secondary fluid. Data for the commercial reference paste $\mathrm{T}$ are also shown. (c) Aspect ratio of electrodes screen-printed through $37 \mu \mathrm{m}$ mesh opening for additive-free paste compared to commercial reference plotted over the yield stress.

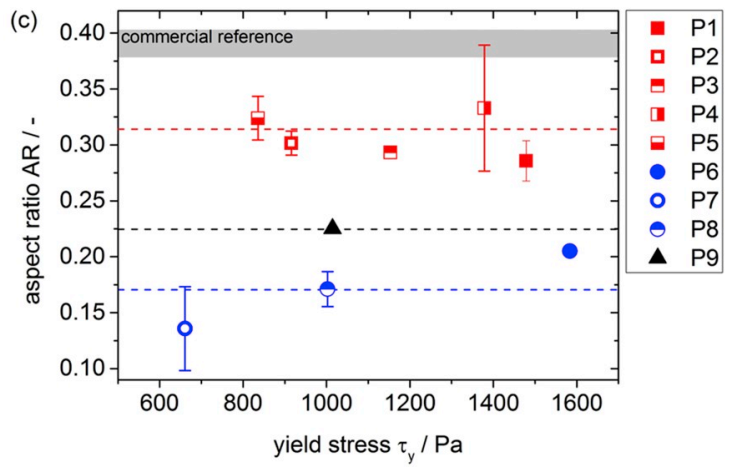

noted that the contact angle values for the secondary fluids SF1, SF2 and SF3 are similar within experimental error, but substantially lower than those of the bulk fluids (see supplementary, Figure 16). Remarkably, pastes P7 and P8 with the low laydown exhibit the highest slip velocities whereas for commercial paste formulations laydown was found to increase with increasing wall slip velocity [47].

The width of the printed finger lines is shown in Fig. 6(b). All formulations exhibit substantial paste spreading, $\mathrm{w}_{\mathrm{f}}$ values vary between $38 \mu \mathrm{m}$ and $60 \mu \mathrm{m}$ for printing tests performed through $37 \mu \mathrm{m}$ mesh openings. Smallest fingers $\left(\mathrm{w}_{\mathrm{f}}<40 \mu \mathrm{m}\right)$ are obtained with commercial reference paste $\mathrm{T}$, but additive-free pastes including SF1 are fairly close with $\mathrm{w}_{\mathrm{f}}=43 \mu \mathrm{m}-48 \mu \mathrm{m}$. However, pastes made with SF2 and SF3 exhibit much higher finger width in the range $\mathrm{w}_{\mathrm{f}}=55 \mu \mathrm{m}-60 \mu \mathrm{m}$. In contrast to earlier findings for commercial pastes [34,47] neither $\tau_{\mathrm{y}}$ (as can be directly seem from Fig. $6(\mathrm{~b}))$ nor the product $\left(\tau_{\mathrm{y}} \cdot \eta_{\text {high }}\right)$ exhibit a correlation with $\mathrm{w}_{\mathrm{f}}$ (graph not shown). Although it needs further investigations to elucidate the different behavior between pastes including SF1 or SF2 and SF3 we can conclude, that additive-free pastes based on the capillary suspension concept can yield similar laydown and finger line width as commercial pastes including polymeric additives, if bulk and secondary fluid are chosen appropriately. Fig. 6(c) shows the aspect ratio AR as a function of yield stress. As expected from laydown and $\mathrm{w}_{\mathrm{f}}$ data the highest aspect ratio is achieved with the commercial paste $(\mathrm{AR}>0.37)$, but the $\mathrm{AR}$ values for the pastes including SF1 are close (AR $=0.28-0.33$ ). Within experimental error the paste P4 including 9\% SF1 and a 40/60 mixture of ethylene glycol/ glycerol exhibits an AR value similar to the commercial paste. AR values for the pastes including SF2 and SF3 are much lower $(\mathrm{AR}=0.13-0.23)$.

Performance of the metallized cells is characterized by the short circuit current density $\mathrm{J}_{\mathrm{SC}}$, open circuit voltage $\mathrm{V}_{\mathrm{OC}}$, fill factor $\mathrm{FF}$, and cell efficiency $\eta_{\text {eff }}$. Corresponding data for all pastes are shown in Fig. 7. As expected from printed finger line morphology, the highest cell efficiency and the best cell performance parameters are achieved for the commercial paste $\mathrm{T}$ but the additive-free pastes including SF1 exhibit only $0.1 \%-0.2 \%$ lower cell efficiency $\eta_{\text {eff. }}$ Within experimental uncertainty $\mathrm{FF}$ and $\mathrm{V}_{\mathrm{OC}}$ values of $\mathrm{SF} 1$ pastes are similar to those of the commercial paste. The $\mathrm{J}_{\mathrm{SC}}$ values are related to shading losses, i.e. line

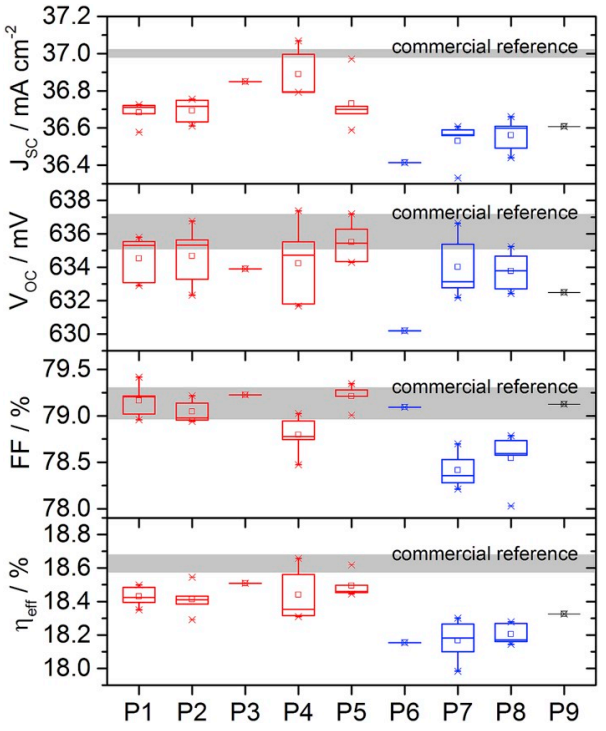

Fig. 7. Cell performance (short circuit current density $\mathrm{J}_{\mathrm{SC}}$, open circuit voltage $\mathrm{V}_{\mathrm{OC}}$, fill factor $\mathrm{FF}$, and cell efficiency $\eta_{\text {eff }}$ ) determined for additive-free silver paste formulation, P1 - P9 (see Table 4) and the commercial reference paste T.

width and accordingly the data for the pastes including SF2 and SF3 are particularly low and within the series of SF1 pastes P4 exhibits the highest $\mathrm{J}_{\mathrm{SC}}$ value consistent with the lowest line width $\mathrm{w}_{\mathrm{f}}$ in that series. For most pastes the $\mathrm{V}_{\mathrm{OC}}$ values are close to that of the reference paste. For pastes $\mathrm{P} 6$ and $\mathrm{P} 9, \mathrm{~V}_{\mathrm{OC}}$ is significantly below the reference value, this can be attributed to the wider electrode lines (see Fig. 6(b)) leading to more damage of the surface passivation. The FF for most pastes is also close to the reference value, only pastes P7 and P8 exhibit a clearly lower FF, this is related to the low laydown of these pastes (see Fig. 6(a)). The cell efficiency $\eta_{\text {eff }}$ is determined by $\mathrm{J}_{\mathrm{SC}}, \mathrm{V}_{\mathrm{OC}}$, and FF. Accordingly the efficiency of pastes including SF2 and SF3 is well below the efficiency of reference paste $\mathrm{T}$, whereas the $\eta_{\text {eff }}$ of pastes made with SF1 are close to the reference value. We obtain almost the same cell 
(a)

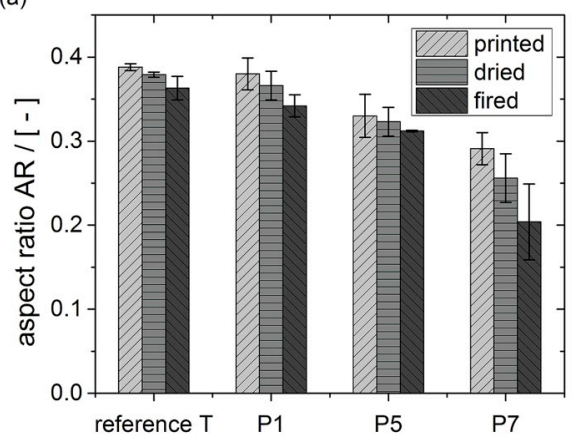

(b)

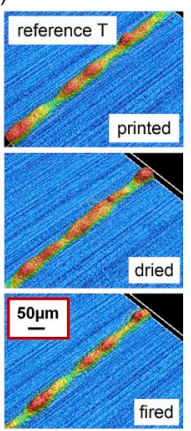

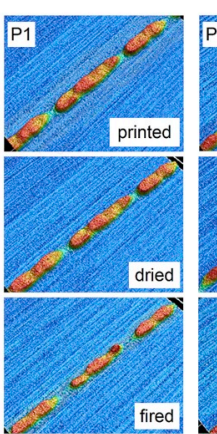

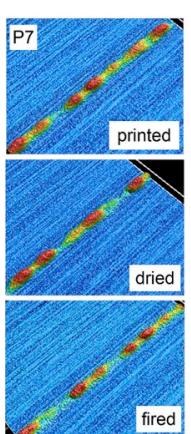

Fig. 8. (a) AR values for pastes P1 ( $80 \mathrm{wt} \%$ glycerol in bulk fluid, SF1 used as secondary fluid), P5 (40 wt $\%$ glycerol, SF1), and P7 (40 wt\% glycerol, SF2), as well as corresponding data for the commercial paste T. (b) Electrode height profiles of reference T, P1, and P7 right after printing, drying, and sintering. The scale bar in the lower left corner is valid for all height profile images. efficiency for all pastes including SF1, therefore we can conclude that high shear viscosity, yield stress or wall slip do not affect the printability, respectively the resulting cell performance. All these quantities vary in a wide range within the series of pastes including SF1. On the other hand pastes including SF2 and SF3 exhibit similar rheological properties but printing properties and cell performance are much worse using these pastes. The physical reason for the distinct performance of pastes including SF1 still remains elusive.

\subsection{Finger line study}

For a deeper understanding how the finally sintered finger lines are formed, printed electrodes are investigated for selected pastes P1, P5, and P7 (see Table 4) as well as reference paste T right after printing, after drying, and after firing and the changes in AR are summarized in Fig. 8(a), data always determined at the same position of the fingers. Corresponding 3D laser scanning microscopy images of the printed, dried and fired electrodes illustrating the 3D height profile are shown in Fig. 8(b). As can be seen from Fig. 8 (a) aspect ratio AR slightly decreases after drying and firing for all pastes due to the removal of the liquid components. This drop is weakest for the commercial paste $\mathrm{T}$ and the additive-free pastes including $S F 1$, whereas the decrease in AR is strongest for paste P7 including SF2 with its low AR even right after printing. The corresponding 3D laser scanning microscopy images shown in Fig. 8(b) clearly show the line interruptions caused by the wires crossing the screen openings. For the commercial paste $T$, these interruptions seem to heal or level out during drying but appear again after firing. In contrast, for the additive-free pastes P1 and P7 such a levelling of line defects is not observed and the width of the finger line interruptions further increases during the firing step. These line interruptions are more pronounced for the additive-free pastes than for the commercial paste T. This disturbs electrical cell properties and hence the electrical cell performance of the commercial paste $\mathrm{T}$ is superior to that of the additive-free pastes.

\subsection{High-speed imaging during screen-printing}

The printing behavior of capillary suspensions in the screen-printing process is captured with high-speed imaging which is described in detail in a previous work [34]. Printing experiments through $35 \mu \mathrm{m}$ mesh openings on a glass substrate are done for three pastes made of the same type M Ag particles and same bulk fluid, pure glycerol, but using different secondary fluids SF1, SF2, or SF3 to change the pastes yield stress as summarized in Table 5. Changes in yield stress occur due to the variation in interfacial tension between the bulk fluid and the different secondary fluids. Here, in contrast to the previous section, capillary forces are supposed to induce formation of a sample-spanning network in the so-called capillary state (see Table 3), i.e. particle clusters form around small droplets of secondary fluid and further assemble into a sample-spanning network. Wall slip behavior is mainly determined by the viscosity of the bulk fluid and the volume fraction of particles. (a)

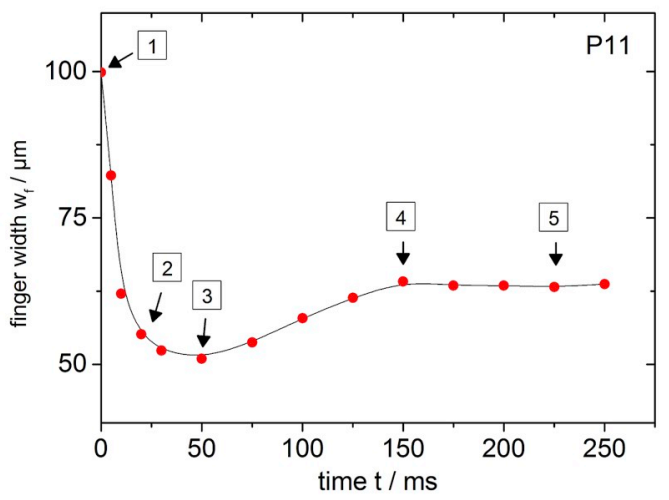

(b)

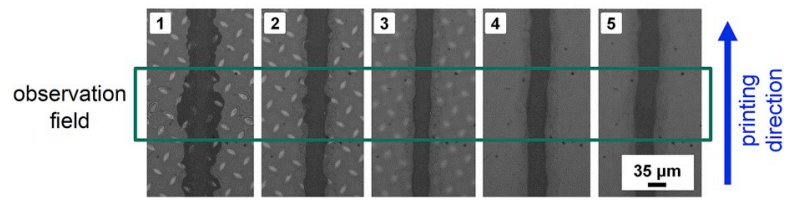

Fig. 9. (a) Finger width development over time determined from high-speed imaging and (b) corresponding cutouts. These cutouts show the bottom side of the finger line printed on a glass plate through $35 \mu \mathrm{m}$ mesh opening at $100 \mathrm{~mm}$ / s printing speed. Paste P11 (see Table 5) is used for these experiments.

Accordingly, slip behavior is similar for all three pastes investigated here. Since particle loading is low and the viscosity of the bulk fluid (glycerol) is high, absolute $\mathrm{v}_{\text {slip }}$ (see supplementary, Figure 17) values as well as the slope $\partial \mathrm{v}_{\text {slip }} / \partial \tau$ are small.

In Fig. 9 the change of finger width over the time, as well as corresponding high-speed images are shown for paste P11, similar behavior is found for P10 and P12. A maximum in finger width is observed when the squeegee brings the screen in contact with the glass plate (substrate). The corresponding picture (1) can be identified by the sharp pattern of the screen on the substrate due to the applied squeegee pressure. This point in time is defined as $\mathrm{t}=0 \mathrm{~ms}$. At this point, comparatively high stresses occur, pastes yield stress is exceeded, i.e. it becomes liquid like, its pronounced strong shear thinning further facilitates spreading of the paste on the glass substrate underneath the screen. This results in a much wider finger widths than the mesh opening. This spreading phenomenon at the squeegee position is not observed for screen-printing pastes containing additives dissolved in the continuous phase providing flow resistance even at high shear rates [34]. Picture (2) is captured after $t=20 \mathrm{~ms}$, when the squeegee passes the observation field but the screen still clings to the substrate. The paste creeps back towards the mesh opening and the finger width exhibits a minimum at $t=50 \mathrm{~ms}$ (Fig. 9(b), image 3 ). This corresponds to the snap-off of the screen. Remarkably, the time of snap-off, or in other words the length of the cling zone, is much shorter than observed earlier for $\mathrm{ZnO}$ model pastes including polymers dissolved in the continuous phase of the paste [34]. The pronounced lateral spreading and 
creep back to the mesh opening is not observed before for commercial pastes and seems to be a characteristic of the additive-free pastes introduced here. Furthermore, high-speed imaging also reveals that a liquid layer with single solid particles remains on the left and right of the printed line after finger width shrinkage.

After snap-off, the paste spreads again and finger line gets wider until reaching an equilibrium after about $150 \mathrm{~ms}$ (Fig. 9(b), image 4 and 5). The finger line width is determined within about $150 \mathrm{~ms}$ after the squeegee passage and thus takes significantly (about $50 \mathrm{~ms}$ ) longer than observed earlier for $\mathrm{ZnO}$ model pastes including polymeric binders and thixotropic agents [34]. It should be noted, that the so-called three interval thixotropy test suggested earlier to characterize the thixotropy and spreading behavior of silver pastes [33] is not appropriate for frontside metallization pastes because the finger line width is determined on a time scale not accessible with classical rotational rheometers as pointed out earlier [34]. The time evolution of finger width for pastes P10 and P12 with experimental uncertainty perfectly agrees with the results shown in Fig. 9 for paste P11. Obviously, the strong variation in yield stress among these pastes does not affect the spreading and receding of the pastes during the printing process. Presumably, high shear viscosity and wall slip which are kept constant here, are more relevant. Resolving this, however, requires further systematic investigations.

\subsection{Knotless screen printing experiments}

Knotless screen is a new screen design especially developed to print fine electrodes $(<30 \mu \mathrm{m})$. The extent of interruption areas in the finger lines caused by the mesh marks is decreased, as the knotless screen, in contrast to well established standard screens, avoids wire intersections within the mesh openings. The wires of the mesh supporting the patterned emulsion polymer are either parallel or perpendicular to the finger line direction. We prepare three additive-free pastes with different bulk fluid composition (Table 6) and perform printing experiments through $27 \mu \mathrm{m}$ mesh opening. The amount of silver particles $(\mathrm{H}-$ type) as well as glass frit (GH-type) and also the secondary fluid SF1 are not changed in these formulations.

The yield stress decreases from P13 to P15, i.e. with decreasing amount of glycerol in the bulk fluid due to the corresponding decrease in interfacial tension (see supplementary, Figure 14). Bulk fluid viscosity and hence the high shear viscosity of the respective pastes also strongly decreases with decreasing glycerol content. In contrast, absolute values of wall slip velocity as well as $\partial \mathrm{v}_{\text {slip }} / \partial \tau$ values increase.

In Fig. 10(a) we show 3D laser scanning microscopy images, corresponding finger line cross-sections (b), EL spectroscopy images (c), as well as the calculated AR data (d) for printed electrodes made of additive-free pastes P13, P14, and P15 and reference $\mathrm{H}$ manufactured with the same Ag and glass frit particles according to a commercial formulation. In knotless screen experiments, finger morphology of the additive-free pastes (Fig. 10(a)) strongly depends on the bulk fluid, i.e. on yield stress and high shear viscosity, which is not seen in standard screen printing experiments discussed above. A sharp edge and narrow finger width is obtained for P13 similar to that achieved with reference paste $\mathrm{H}$ containing non-volatile additives. Although the edges obtained with paste P13 seem to be formed sharper than for the reference paste $\mathrm{H}$, the aspect ratio AR is slightly higher for the latter and this is presumably due to the lower silver deposit with paste P13 $(90 \mathrm{mg} /$ wafer vs. $120 \mathrm{mg}$ /wafer for reference $\mathrm{H}$ ). However, the electrical cell performance for wafers metallized with paste P13 (data not determined) is expected to be significantly lower than that achieved with the reference paste due to fluctuations in finger height (see Fig. 10(b)) and potential line interruptions. Corresponding contacting defects are clearly seen in the EL spectroscopy image (see Fig. 10(c)) of the wafer printed with paste P13. The dark fields between the printed lines indicate poor contacting. In contrast, a bright EL spectroscopy image is obtained for the wafer printed with paste $\mathrm{H}$ indicating good interruption-free contacting. All in all, the aspect ratio is higher and the silver laydown is lower in both cases compared to printing through a standard screen with otherwise similar specifications. Printing trials using a standard screen with similar mesh opening $(27 \mu \mathrm{m})$ resulted in $40 \%$ higher silver deposit for reference paste $\mathrm{H}$ as well as the additive-free system P13. Knotless screen technology was introduced to enable reduced silver consumption without loss in cell efficiency [28]. This concept is confirmed here, too.

The additive-free pastes P14 and P15 show an extended spreading with $\mathrm{w}_{\mathrm{f}}$ much larger than the mesh opening and strong fluctuations in line width as well as height. P15 additionally exhibits substantial paste debris, i.e. individual $\mathrm{Ag}$ particles are laterally disposed from the printed line. This results in aspect ratios $\mathrm{AR}<0.3$ and many contacting defects as obvious from corresponding data in Fig. 10(d). These pastes are clearly not suitable for knotless screen printing. The reason for this drastic change in printing behavior is not clear yet. Similar changes in yield stress, high shear viscosity or contact angle between bulk fluid and wafer upon changing glycerol/ethylene glycol mixing ratio are not shown up in standard screen printing trials. Presumably, the higher slip velocity observed for this series of pastes compared to the pastes $\mathrm{P}$ - P9 used for standard screen printing causes this phenomenon. Slip is more pronounced here due to the higher particle loading of the pastes, and for the narrower mesh opening $(27 \mu \mathrm{m})$ slip contributes stronger to paste transport than in the standard screen printing tests done with $37 \mu \mathrm{m}$ mesh opening. The relevance of slip phenomena for screenprinting needs further investigation.

\subsection{Pattern Transfer printing}

Pattern Transfer Printing ${ }^{\mathrm{TM}}$, a contactless printing technology, is applied to print fine silver lines of additive-free paste on the Si-wafer. This paste transfer concept is supposed to yield defect free fine electrodes at a high printing speed [15,29]. Here we want to elucidate whether our additive-free paste formulation concept is suitable for PTP, too. Pastes are made of $\mathrm{Ag}$ particles type $\mathrm{T}$ and $\mathrm{M}$ forming capillary
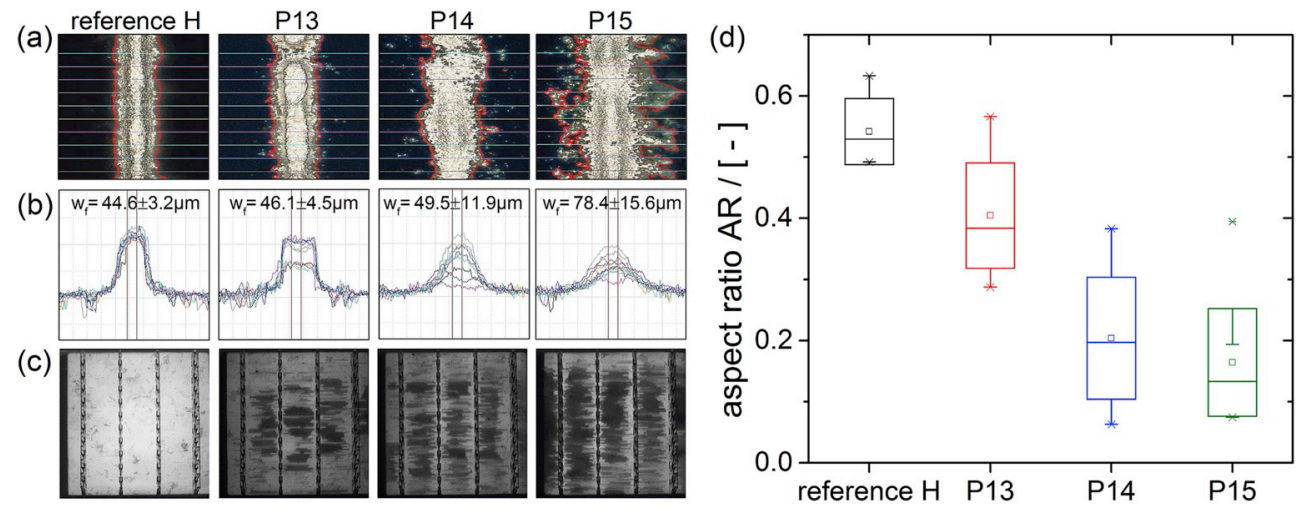

Fig. 10. Characterization of electrodes made from reference $\mathrm{H}, \mathrm{P} 13, \mathrm{P} 14$, and $\mathrm{P} 15$ applied with knotless screen through $27 \mu \mathrm{m}$ mesh opening. (a) Top view of printed electrodes obtained from 3D laser scanning microscopy imaging and finger edge detection. (b) Corresponding finger line crosssections determined at 10 positions along the printed finger lines with identical spacing in between. (c) EL spectroscopy images representing finger lines with interruptionfree contacting (bright areas) and non-contacting due to printing defects like finger line interruptions (dark areas). (d) Corresponding AR data calculated from finger height and finger width data. 
(a)

(1)

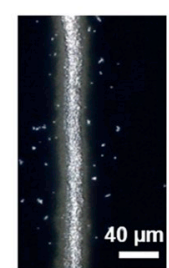

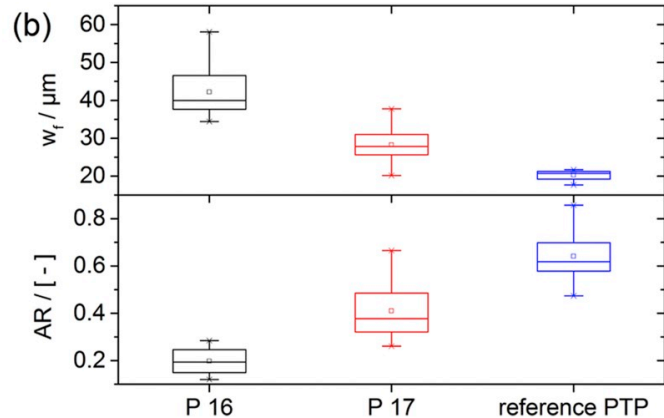

Fig. 11. (a) 3D laser scanning microscopy image and (b) corresponding finger morphology characterization ( $w_{\mathrm{f}}$ and calculated AR) for P16, P17 reference PTP pastes.

networks in pendular (P16) and capillary state (P17) (see Table 3). For these experiments we also use different bulk fluid compositions but the same type and amount of secondary fluid (SF1). Glass frit type GT is included in both formulations but the glass frit amount is slightly different. Yield stress, high shear viscosity and the wall slip properties of these pastes are significantly different.

Fig. 11(a) shows laser scanning images of the printed lines and Fig. 11(b) displays corresponding geometrical data characterizing finger line morphology. The cross-sectional area $\mathrm{A}_{\mathrm{f}}$, i.e. the silver deposit, is the same for all pastes and apparently all pastes completely detach from the trenched polymer substrate (data not shown here). The customized reference paste PTP exhibits a line width $\mathrm{w}_{\mathrm{f}} \sim 20 \mu \mathrm{m}$ and an aspect ratio $\mathrm{AR}>0.6$ closely resembling the geometry of the trenches in the substrate. Obviously, this paste hardly spreads when deposited on the wafer. In contrast, the additive-free paste P17 spreads significantly resulting in a $50 \%$ larger $\mathrm{w}_{\mathrm{f}}$ compared to the trench width. Accordingly, $\mathrm{AR} \approx 0.4$ is clearly lower than for the reference paste, but still in a technically reasonable range. Spreading is even more pronounced for paste P16 and in addition a lot of debris is visible off the printed lines, consequently $\mathrm{AR} \approx 0.2$ is very low.

Fig. 12(a) displays data characterizing electrical cell performance, Fig. 12(b) the resulting line resistance and in Fig. 12(c) EL spectroscopy images are shown.

Cell efficiency and fill factor of the reference paste are far higher than those of the additive-free pastes. The differences in short circuit current $J_{s c}$ reflect the shading losses and directly correlate to the

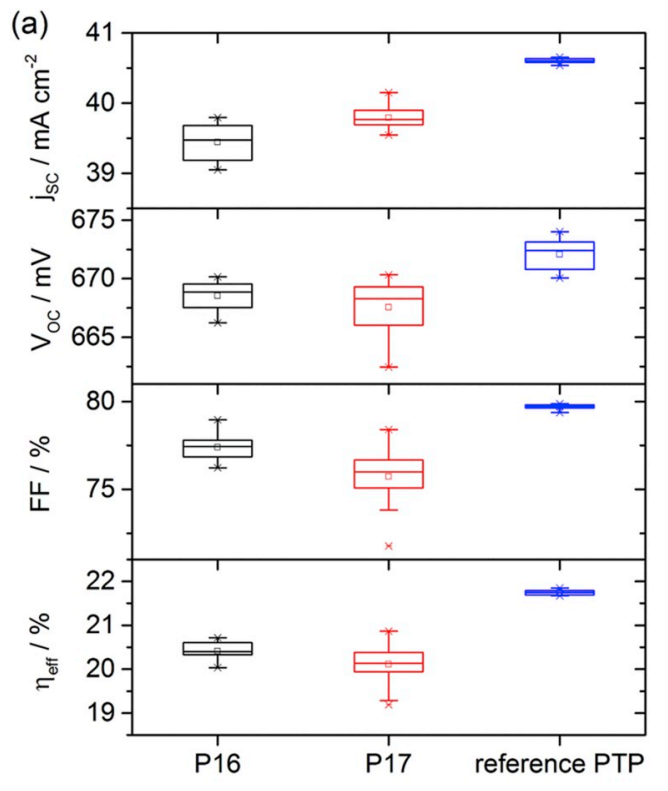

differences in $w_{\mathrm{f}}$ and AR data shown in Fig. 11(b). The poor electrical performance, especially of paste $\mathrm{P} 17$, is mostly due to contacting defects as indicated by the high line resistance $\mathrm{R}_{\mathrm{L}}$ and the strong scatter in the measured $R_{L}$ values especially for P17 (see Fig. 12(b)). These contacting faults are also visible in the EL spectroscopy images shown in Fig. 12(c), corresponding dark regions shown up in the lower and left border regions for pastes P16 and P17, while the image corresponding to the reference paste PTP is essentially defect free. Visual inspection of the metallized wafers after drying reveals that the lines printed with pastes P16 and P17 partly detached from the wafer particularly in the border areas of the wafers. The air flow in the drying oven seems to peel off the fine lines. This seems to be a major challenge for improving the electrical performance of cells metallized with the new additive-free pastes, i.e. adhesion between wafer and printed finger lines has to be improved without addition of non-volatile, polymeric additives.

\section{Conclusion}

Non-volatile free silver paste formulation based on the so-called capillary suspension concept is a simple, versatile and cost-efficient platform to manufacture highly conductive silver pastes suitable for different printing technologies utilized in front-side metallization of silicon ( $\mathrm{Si}$ ) solar cells. Pastes consist of silver particles, glass frit and two immiscible fluids. Capillary forces induced by the secondary fluid added only in small amounts $(<5 \mathrm{vol} \%)$ induce the formation of a percolating particle network. This network provides extended self-life

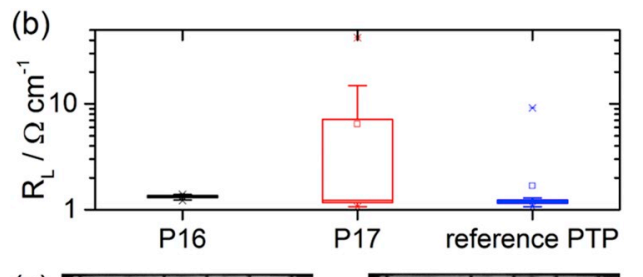

(c)

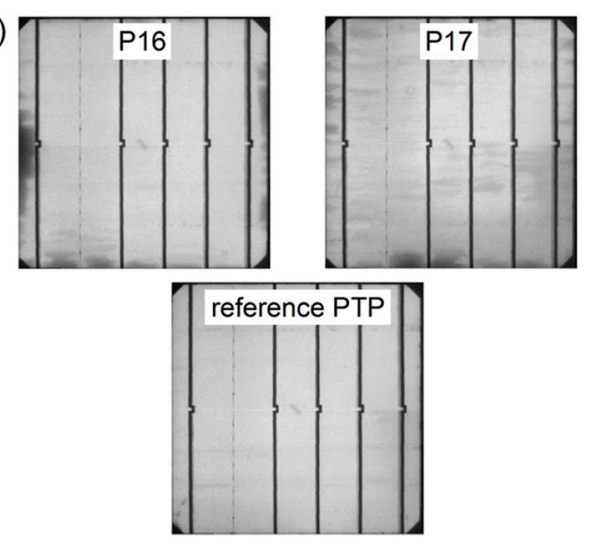

Fig. 12. (a) Cell performance $\left(\mathrm{J}_{\mathrm{SC}}, \mathrm{V}_{\mathrm{OC}}, \mathrm{FF}\right.$, and $\eta_{\mathrm{eff}}$ ) determination, (b) line resistance $\mathrm{R}_{\mathrm{L}}$ and (c) EL images obtained for additive-free paste formulation (P16 and P17) compared to commercial reference paste PTP. 
and distinct flow properties adjustable in a wide range according to the demands of the respective printing process. Pastes have a low degree of agglomeration which is beneficial especially for printing narrow finger lines. The absence of non-volatile binders or thixotropic agents guarantees that the sintered finger lines are free of residual carbon impurities.

Printing tests with standard screen design through $37 \mu \mathrm{m}$ mesh openings are performed with a series of pastes including the same type and amount of silver particles and glass frit. Composition of bulk fluid (different mixing ratios of ethylene glycol and glycerol) as well as type and amount of secondary fluid is varied in order to cover a broad range of yield stress, high shear viscosity and wall slip velocities. No clear correlation between these flow properties and printing results, i.e. cell performance can be retrieved from these experiments. However, all pastes including SF1 as secondary fluid exhibit printed finger line morphologies and electrical cell performance data close to that of a commercial reference paste including non-volatile additives. The physical reason for this remains elusive. We hypothesize the phenomenon is related to differences in the wetting behavior on the Si-wafer. This will be addressed in future research and our high-speed imaging set-up allowing for a direct imaging of the printing process on transparent model substrates can shed some light on this important application aspect.

The commercial paste exhibits the lowest drop of aspect ratio AR from printing to firing and printed defects (variations of line height) level out during drying. Line interruptions are more pronounced for the additive-free pastes and further increase during firing. This is a major reason for the lower electrical cell performance achieved with the latter pastes compared to the commercial system.

High-speed imaging is used to monitor paste spreading during screen-printing of additive-free pastes on a glass substrate. Pastes exhibit a strong lateral spreading far beyond the mesh opening when the squeegee brings the screen into contact with the substrate. Then the paste creeps back and a minimum line width is observed when the screen snaps off. Subsequently, the paste spreads again to achieve an equilibrium value after about $150 \mathrm{~ms}$. This spreading kinetics is distinctly different from what was reported for $\mathrm{ZnO}$ pastes including nonvolatile additives [34] and seems to be characteristic for capillary suspension type pastes. Future high-speed imaging studies will help to find appropriate printer settings (e.g. squeegee pressure) to reduce paste spreading, and also to understand how this is affected by paste composition.

Additive-free pastes are also suitable for knotless screen printing and similar as for commercial pastes silver deposit can be reduced and AR can be increased compared to printing with a conventional screen. However, printing results strongly depend on bulk fluid composition (secondary fluid type and amount is kept constant in this series of experiments). Paste spreading and line interruptions strongly increase with decreasing yield stress and high shear viscosity as well as increasing wall slip. Since in this series of experiments particle loading is higher and mesh opening is narrower than in the standard screen printing trials reported above, we hypothesize that particularly slip phenomena may have a dominant effect on printing performance. Laser scanning microscopy of the printed lines as well as EL spectroscopy imaging of sintered wafers reveal that line interruptions and contacting defects are more pronounced for the additive-free pastes than for the commercial reference paste.

Non-volatile free paste formulations are also suitable for PTP. Depending on the paste formulation we obtain almost interruption-free finger widths $\mathrm{w}_{\mathrm{f}} \approx 30 \mu \mathrm{m}$ with high AR $(\approx 0.5)$ from PTP technology. Cell performance again suffers from contacting defects which according to visual inspection are caused here by poor adhesion of the deposited lines on the wafer.

Our results demonstrate that the additive-free paste formulation concept based on the capillary suspension phenomenon is applicable in standard screen, knotless screen as well as PTP technologies. With appropriate choice of bulk and secondary fluid, electrode morphologies and cell performance data can be achieved similar to that obtained with commercial silver pastes including non-volatile additives presumably resulting in residual carbon impurities in the sintered electrodes.

However, paste composition has to be further modified and also printing parameters have to be adjusted to decrease paste spreading and line interruptions. Beyond that, also adhesion of printed lines to the wafer has to be improved in order to excel electrical cell performance achieved with state-of-the-art silver pastes, finally reducing the silver consumption needed for harvesting solar energy.

\section{Acknowledgements}

The authors would like to thank C. Xu for performing high-speed imaging experiments, $\mathrm{O}$. Süß and K. Tedjokusuma for experimental support especially in contact angle and surface tension measurements. Furthermore, we would like to thank V. Zibat for supporting us with EDX images. C. Yüce gratefully acknowledges financial support by the 100 prozent erneuerbar stiftung. Finally, we acknowledge financial support from the Federal Ministry for Economic Affairs and Energy, Germany (Grant no. 0325775G).

\section{References}

[1] European Photovoltaic Industry Association, Connecting the Sun - Solar Photovoltaics on the Road to Large-Scale Grid Integration, (2012).

[2] J. Wilkes, C. Kjaer, R. Gruet, Pure Power-Wind Energy Targets for 2020 and 2030, European Wind Energy Association, 2011.

[3] European Wind Energy Association, Wind in Power 2016 European Statistics, (2017).

[4] A. Riverola, A. Mellor, D. Alonso Alvarez, L. Ferre Llin, I. Guarracino, C.N. Markides, D.C. Paul, D. Chemisana, N. Ekins-Daukes, Mid-infrared emissivity of crystalline silicon solar cells, Sol. Energy Mater. Sol. Cells 174 (2018) 607-615 October 2017

[5] N. Zin, K. McIntosh, S. Bakhshi, A. Vázquez-Guardado, T. Kho, K. Fong, M. Stocks, E. Franklin, A. Blakers, Polyimide for silicon solar cells with double-sided textured pyramids, Sol. Energy Mater. Sol. Cells 183 (2018) 200-204 October 2017.

[6] E.L. Ralph, Recent advancements in low cost solar cell processing, 11th Photovoltaic Specialists Conference, vol. 1, 1975, p. 315.

[7] M.B. Field, L.R. Scudder, Application of thick-film technology to solar cell fabrication, 12th Photovoltaic Specialists Conference, 1976, pp. 303-308.

[8] International Technology Roadmap for Photovoltaic (ITRPV), Results 2017 Including Maturity Report 2018, ITRPV, 2018 [Online]. Available: www.itrpv.net/. cm4all/uproc.php/0/ITRPV Ninth Edition 2018 including maturity report 20180904.pdf? cdp $=a \&_{-}=165 a 39 b b f 90$.

[9] M. Aoki, K. Nakamura, T. Tachibana, I. Sumita, H. Hayashi, H. Asada, Y. Ohshita, "30 $\mu \mathrm{m}$ fine-line printing for solar cells, Photovoltaic Specialists Conference (PVSC), 2013 IEEE 39th, 2013, pp. 2162-2166.

[10] N.S. Lewis, Toward cost-effective solar energy use, Science 315 (2007) 798-801.

[11] M. Ju, Y.J. Lee, J. Lee, B. Kim, K. Ryu, K. Choi, K. Song, K. Lee, C. Han, Y. Jo, J. Yi, Double screen printed metallization of crystalline silicon solar cells as low as $30 \mu \mathrm{m}$ metal line width for mass production, Sol. Energy Mater. Sol. Cells 100 (2012) 204-208.

[12] A.S.K. Chunduri, M. Schmela, Market Survey Screen Printers 2018, Taiyangnews, 2018.

[13] M. Pospischil, M. Klawitter, M. Kuchler, M. Jahn, R. Efinger, R. Schwarz, L. Wende, M. König, F. Clement, D. Biro, "High speed dispensing with novel 6" print head, Energy Procedia 98 (2016) 61-65.

[14] A. Lorenz, A. Kalio, G.T. Hofmeister, S. Nold, L. Friedrich, A. Kraft, J. Bartsch, D. Wolf, M. Dreher, F. Clement, D. Biro, Flexographic printing - high troughput technology for fine line seed layer printing on silicon solar cells, 28th European Photovoltaic Solar Energy Conference and Exhibition, 2013, pp. 1017-1023.

[15] J. Lossen, M. Matusovsky, A. Noy, C. Maier, M. Bähr, Pattern transfer printing (PTP) for c-Si solar cell metallization, Energy Procedia 67 (2015) 156-162.

[16] C. Ballif, D.M. Huljić, G. Willeke, A. Hessler-Wyser, Silver thick-film contacts on highly doped n-type silicon emitters: structural and electronic properties of the interface, Appl. Phys. Lett. 82 (12) (2003) 1877-1880

[17] G.C. Cheek, R.P. Mertens, R. van Overstraeten, L. Frisson, Thick-film metallization for solar cell applications, IEEE Trans. Electron Devices 31 (5) (1984) 602-609.

[18] L. Wang, C. Guo, R. M. Cosimano, and W. Zhang, "Conductive thick film paste for solar cell contacts," US 2013/0228207 A1, 2013.

[19] S.E. Habas, H.A.S. Platt, M.F.A.M. van Hest, D.S. Ginley, "Low-Cost inorganic solar Cells : from ink to printed device, Chem. Rev. 110 (2010) 6571-6594. 
[20] L. Song, C. Chen, T. Guo, W. Zhang, Organic Vehicle for Electroconductive Paste, (2013) 12007476.0 (EP 2590177 A2)

[21] W. J. Borland and J. D. Summers, "Conductive paste for fine-line high-aspect-ratio screen printing in the manufacture of semiconductor devices," US 2013/0180583 A1, 2013.

[22] J.D. Fields, M.I. Ahmad, V.L. Pool, J. Yu, D.G. Van Campen, P.A. Parilla, M.F. Toney, M.F.A.M. van Hest, The formation mechanism for printed silver-contacts for silicon solar cells, Nat. Commun. 7 (2016) 1-7.

[23] E. Koos, N. Willenbacher, Capillary forces in suspension rheology, Science 84331 (2011) 897-900.

[24] M. Schneider, E. Koos, N. Willenbacher, Highly conductive, printable pastes from capillary suspensions, Sci. Rep. 6 (2016) 1-10.

[25] E. Koos, N. Willenbacher, Particle configurations and gelation in capillary suspensions, Soft Matter 8 (14) (2012) 3988-3994.

[26] E. Koos, J. Johannsmeier, L. Schwebler, N. Willenbacher, Tuning suspension rheology using capillary forces, Soft Matter 8 (2012) 6620-6628.

[27] Y. Zhang, L. Zhang, L. Jiang, L. Song, C. Guo, V. Dua, H. Yang, E. Kim, C. Chen, Knotless screen printing for crystalline silicon solar cells, 7th Workshop on Metallization Konstanz, 2017.

[28] A. Lorenz, M. Linse, H. Frintrup, M. Jeitler, A. Mette, M. Lehner, R. Greutmann, H. Brocker, M. König, D. Erath, F. Clement, Screen printed thick film metallization of silicon solar cells - recent developments and future perspectives, In 35th European Photovoltaic Solar Energy Conference and Exhibition, 2018, pp. 819-824.

[29] A. Adrian, D. Rudolph, J. Lossen, M. Matusovsky, V. Chandrasekaran, Benefits of pattern transfer printing method for finger metallization on silicon solar cells, In 35th European Photovoltaic Solar Energy Conference and Exhibition, 2018, pp. 434-438.

[30] I.B. Cooper, R. Stephenson, P. Ferraro, Polyalkylene carbonate binders for cleaner burning thick film Ag paste: comparison to commercially available Ag pastes, In Photovoltaic Specialist Conference, (PVSC), 2016 IEEE 43th, 2016, pp. 2882-2884.

[31] C. Yüce, N. Willenbacher, Challenges in rheological characterization of highly concentrated suspensions - a case study for screen-printing silver pastes, J. Vis. Exp. (2017) 1-17.

[32] C. Yüce, M. König, N. Willenbacher, Rheology and screen-printing performance of model silver pastes for metallization of Si-solar cells, Coatings 8 (11) (2018) 406.

[33] J. Hoornstra, A.W. Weeber, H.H.C. de Moor, W.C. Sinke, The importance of paste rheology in improving fine line, thick film screen printing of front side metallization, Neth. Energy Res. Found. ECN (1997) 823-826 Proc. 14th EC PVSEC, Barcelona, Spain.

[34] C. Xu, N. Willenbacher, How rheological properties affect fine-line screen printing of pastes: a combined rheological and high-speed video imaging study, J. Coat.
Technol. Res. (2018) 1-12.

[35] F. Bashforth, J.C. Adams, An Attempt to Test the Theories of Capillary Action: by Comparing the Theoretical and Measured Forms of Drops of Fluid, Univ. Press, 1883.

[36] B. Song, J. Springer, Determination of interfacial tension from the profile of a pendant drop using computer-aided image processing, J. Colloid Interface Sci. 184 (1996) 64-76

[37] E.Y. Arashiro, N.R. Demarquette, Use of the pendant drop method to measure in terfacial tension between molten polymers, Mater. Res. 2 (1) (1999) 23-32.

[38] W.C. Hamilton, A technique for the characterization of hydrophilic solid surfaces, J. Colloid Interface Sci. 40 (2) (1972) 219-222.

[39] W. Zhang, B. Hallström, Membrane Characterization Using the Contact Angle Technique I. Methodology of the Captive Bubble Technique,” Desalin, vol. 79 Elsevier Sci. Publ. B.V., Amsterdam, 1990, pp. 1-12.

[40] K. Grundke, T. Bogumil, C. Werner, A. Janke, K. Pöschel, H.-J. Jacobasch, Liquidfluid contact angle measurements on hydrophilic cellulosic materials, Colloids Surfaces, A Physicochem. Eng. Asp. 116 (1996) 79-91.

[41] D.K. Owens, R.C. Wendt, Estimation of surface free energy of polymers, J. Appl. Polym. Sci. 13 (1969) 1741-1747.

[42] E. Koos, Capillary suspensions: particle networks formed through the capillary force, Curr. Opin. Colloid Interface Sci. 19 (6) (2014) 575-584.

[43] S.S. Velankar, A non-equilibrium state diagram for liquid/fluid/particle mixtures, Soft Matter 11 (43) (2015) 8393-8403.

[44] Elementitis Specialities, Rheology Handbook - A Practical Guide to Rheological Additives, (2008).

[45] H.A. Barnes, J.O. Carnali, The vane-in-cup as a novel rheometer geometry for shear thinning and thixotropic materials, J. Rheol. 34 (6) (1990) 841-866.

[46] H. Anthony, Q.D. Nguyen, Rotating vane rheometry - a review, J. Non-Newtonian Fluid Mech. 98 (2001) 1-14.

[47] C. Xu, M. Fies, N. Willenbacher, Impact of wall slip on screen printing of front-side silver pastes for silicon solar cells, IEEE J. Photovoltaics 7 (1) (2017) 129-135.

[48] K. Bothe, J. Schmidt, T. Weber, P. Altermatt, B. Fischer, R. Brendel, Electroluminescence imaging as an in-line characterization tool for solar cell production, 21st European Photovoltaic Solar Energy Conference, 2006, pp. 597-600.

[49] H.H. Berger, Contact resistance and contact resistivity, J. Electrochem. Soc. Solid State Sci. Technol. 119 (4) (1972) 507.

[50] D.K. Schroder, D.L. Meier, "Solar cell ' contact resistance-A review, IEEE Trans. Electron Devices 31 (5) (1984) 637-647.

[51] J. Mewis, N.J. Wagner, Colloidal Suspension Rheology, Cambridge University Press, 2012. 
Karlsruher Institut für Technologie

\section{Repository KITopen}

Dies ist ein Postprint/begutachtetes Manuskript.

Empfohlene Zitierung:

Yüce, C.; Okamoto, K.; Karpowich, L.; Adrian, A.; Willenbacher, N.

Non-volatile free silver paste formulation for front-side metallization of silicon solar cells. 2019. Solar energy materials \& solar cells, 200.

doi: $\underline{10.5445 / I R / 1000096656}$

Zitierung der Originalveröffentlichung:

Yüce, C.; Okamoto, K.; Karpowich, L.; Adrian, A.; Willenbacher, N.

Non-volatile free silver paste formulation for front-side metallization of silicon solar cells. 2019. Solar energy materials \& solar cells, 200, Article No. 110040.

doi:10.1016/j.solmat.2019.110040

Lizenzinformationen: CC BY NC ND-Lizenz 4.0 